\title{
Effects of the short-term application of pantoprazole combined with aspirin and clopidogrel in the treatment of acute STEMI
}

\author{
PENG WEI $^{1}$, YI-GANG ZHANG ${ }^{1}$, LIN LING $^{2}$, ZI-QI TAO ${ }^{3}$, LI-YA JI ${ }^{1}$, JIE BAI $^{4}$, BIN ZONG $^{1}$, \\ CHUN-YING JIANG ${ }^{1}$, QIAN ZHANG ${ }^{1}$, QIANG FU ${ }^{1}$ and XIANG-JUN YANG ${ }^{2}$ \\ ${ }^{1}$ Department of Cardiology, Xuzhou Central Hospital, Xuzhou, Jiangsu 221009; ${ }^{2}$ Department of Cardiology, \\ The First Affiliated Hospital, Soochow University, Suzhou, Jiangsu 215006; ${ }^{3}$ Departments of Science \\ and Education, Xuzhou Central Hospital, Xuzhou, Jiangsu 221009; ${ }^{4}$ Department of Geriatrics, \\ Changhai Hospital of The Second Military Medical University, Shanghai 200433, P.R. China
}

Received December 31, 2015; Accepted August 22, 2016

DOI: 10.3892/etm.2016.3693

\begin{abstract}
The aim of the present study was to determine the effects of the short-term application of pantoprazole on the co-treatment of acute ST-segment elevation myocardial infarction (STEMI) with aspirin and clopidogrel. A total of 207 acute patients showing primary symptoms of STEMI, who received successful emergent percutaneous coronary intervention treatment during hospitalization were randomly divided into two groups. In the test group proton pump inhibitors (PPIs), the patients were treated with a combination of aspirin and clopidogrel and pantoprazole, while those in the control group were treated only with aspirin and clopidogrel. Gastrointestinal bleeding events and major adverse cardiac events (MACEs) were observed in the two groups. Gastrointestinal bleeding events of the two groups mostly occurred within the first week of hospitalization, although the incidence in the PPIs group was significantly higher than that in the control group $(\mathrm{p}<0.05)$. However, no significant difference was observed for the incidence of MACEs between the two groups ( $p>0.05)$. In conclusion, the results of the present study have shown that the short-term application of pantoprazole combined with aspirin and clopidogrel does not increase the incidence of MACEs in patients with acute STEMI, reduces the risk of gastrointestinal bleeding, and is thus worth promoting clinically, particularly for high-risk groups.
\end{abstract}

Correspondence to: Dr Qiang Fu, Department of Cardiology, Xuzhou Central Hospital, 199 Liberation of South Road, Xuzhou, Jiangsu 221009, P.R. China

E-mail: fuqiang@medmail.com.cn

Dr Xiang-Jun Yang, Department of Cardiology, The First Affiliated Hospital, Soochow University, 188 Shizi Street, Suzhou, Jiangsu 215006, P.R. China

E-mail: pennsylwestern@163.com

Key words: ST-segment elevation myocardial infarction, pantoprazole, aspirin, clopidogrel, major adverse cardiac events

\section{Introduction}

Acute ST-segment elevation myocardial infarction (STEMI), with unexpected onset, high sudden death rate and poor prognosis, is a critical acute coronary syndrome. The implementation of percutaneous coronary intervention (PCI) has lead to a reduction in the mortality of STEMI (1). However, the stress response of patients themselves and enhanced antithrombotic drugs have increased the risks of gastrointestinal bleeding (2). Thus, it is clinically vital to use proton pump inhibitors (PPIs) to prevent ulcers resulting from stress.

Previous findings have shown that PPIs possibly interact with clopidogrel and reduce antiplatelet effects, and thus increase the risk of death and re-hospitalization of patients $(3,4)$.

The present study aimed to investigate the effects of the short-term application of pantoprazole together with the co-treatment of aspirin plus clopidogrel for myocardial infarction with aspirin plus clopidogrel, providing a theoretical basis that may be utilized in the clinic.

\section{Materials and methods}

Clinical data. A total of 207 acute patients who showed primary symptoms of STEMI and successfully underwent emergent PCI treatment during hospitalization in the Department of Cardiology of Xuzhou Central Hospital (Jiangsu, China) from December, 2012 to December, 2014, were randomly divided into two groups of dual antiplatelet therapy (aspirin plus clopidogrel). The test group (PPIs), which received co-treatment of aspirin and clopidogrel and pantoprazole, comprised 123 patients (69 men and 54 women), with an average age of $59.32 \pm 9.14$ years. The control group (treatment with aspirin and clopidogrel), comprised 84 patients ( 48 men and 36 women), with an average age of $58.47 \pm 10.06$ years.

The selected patients adhered to the WHO diagnostic criteria of STEMI: i) typical chest pain duration of $>30 \mathrm{~min}$; ii) ST-segment elevation in electrocardiogram in the lead of at least two limbs or two precordial leads $>1 \mathrm{~mm}$; and iii) dynamic 
Table I. Comparison of gastrointestinal bleeding events between the two groups (\%).

\begin{tabular}{|c|c|c|c|c|c|}
\hline Groups & Cases & $\begin{array}{c}\text { Gastrointestinal } \\
\text { bleeding events } \\
\text { No. }(\%)\end{array}$ & $\begin{array}{c}\text { Recessive bleeding } \\
\text { No. }(\%)\end{array}$ & $\begin{array}{c}\text { Minor bleeding } \\
\text { No. }(\%)\end{array}$ & $\begin{array}{c}\text { Severe } \\
\text { gastrointestinal } \\
\text { bleeding } \\
\text { No. }(\%)\end{array}$ \\
\hline PPIs & 123 & $2(1.6)^{\mathrm{a}}$ & $1(0.8)^{\mathrm{a}}$ & $1(0.8)^{\mathrm{a}}$ & $0(0.0)^{\mathrm{a}}$ \\
\hline Control & 84 & $13(15.5)$ & $5(6.0)$ & $5(6.0)$ & $3(3.6)$ \\
\hline$\chi^{2}$-value & & 14.245 & 4.684 & 4.684 & 4.457 \\
\hline P-value & & 0.000 & 0.030 & 0.030 & 0.035 \\
\hline
\end{tabular}

${ }^{\mathrm{a} C o m p a r e d ~ t o ~ c o n t r o l ~ g r o u p, ~} \mathrm{p}<0.05$. PPIs, proton pump inhibitors.

Table II. Comparison of MACEs between the two groups of patients (\%).

\begin{tabular}{|c|c|c|c|c|c|c|}
\hline Groups & Cases & $\begin{array}{l}\text { Secondary } \\
\text { heart failure } \\
\text { No. }(\%)\end{array}$ & $\begin{array}{c}\text { Severe } \\
\text { arrhythmia } \\
\text { No. }(\%)\end{array}$ & $\begin{array}{c}\text { Post-infarction } \\
\text { angina } \\
\text { No. }(\%)\end{array}$ & $\begin{array}{c}\text { Recurrent myocardial } \\
\text { infarction } \\
\text { No. }(\%)\end{array}$ & $\begin{array}{c}\text { Cardiogenic death } \\
\text { No. }(\%)\end{array}$ \\
\hline PPIs & 117 & $12(10.2)$ & $4(3.4)$ & 23 (19.6) & $6(5.1)$ & $3(2.5)$ \\
\hline Control & 80 & $8(10.0)$ & $3(3.7)$ & $16(20.0)$ & $4(5.0)$ & $2(2.5)$ \\
\hline$\chi^{2}$-value & & 0.003 & 0.015 & 0.003 & 0.002 & 0.001 \\
\hline P-value & & 0.953 & 0.902 & 0.953 & 0.968 & 0.978 \\
\hline
\end{tabular}

MACEs, major adverse cardiac events; PPIs, proton pump inhibitors.

changes in serum cardiac enzymes with surgery indications for emergent PCI. Exclusion criteria for the patients were: i) with other heart diseases; ii) with severe heart failure (Killip grade III-IV) and liver and kidney dysfunction; iii) combined with acute and chronic infections, gastrointestinal ulcers, blood diseases, malignancies, rheumatic connective tissue diseases and other immune system disorders; iv) with recent surgery or trauma with previous PCI surgery; v) with diabetes and other endocrine diseases; and vi) with cerebrovascular and peripheral vascular diseases and other diseases.

Antiplatelet medicine. Immediately after admission the patients received (before PCI) aspirin tablets $(500 \mathrm{mg}$ ) by chewing and clopidogrel orally at a loading dose of $600 \mathrm{mg}$. The patients were then postoperatively administered clopidogrel at a dose of $75 \mathrm{mg}$ and Bayer aspirin (Yangtze River Pharmaceutical Co., Ltd., Taizhou, China) at $100 \mathrm{mg}$, both by oral administration, daily, and enoxaparin sodium was used concomitantly for 5 to 8 days.

Application of pantoprazole in PPIs group. Patients in the PPIs group were treated with intravenous injection of pantoprazole at $40 \mathrm{mg}$ immediately after admission for 3 to 5 days, on a daily basis. followed by oral administration at $40 \mathrm{mg}$, daily, until discharge.

Administration of other medicines. Patients showing relevant indications during hospitalization received statins, $\beta$-blockers and angiotensin-converting enzyme inhibitors (ACEIs) or angiotensin receptor blockers (ARBs) or other medicine for the treatment.

Observation of gastrointestinal bleeding events. Gastrointestinal bleeding was observed in the two groups during hospitalization. A gastrointestinal ulcer due to stress was identified from one of the following signs especially during the first week of hospitalization: vomit; brown, red or black gastric juice, or bloody stool; black stool in parallel with positive result of occult blood test; unexplained decline in hemoglobin (5); and recessive bleeding without the abovementioned signs: positive results only in occult blood test, no significant bleeding; severe gastrointestinal bleeding: obvious vomiting of blood, bloody stool or sharp decline of hemoglobin; minor bleeding: bleeding between recessive and gastrointestinal bleeding.

Observation of major adverse cardiac events. During the first 6 months of illness (including the hospitalization period), the major adverse cardiac events (MACEs) of the two groups were recorded, including secondary onset of heart failure, severe arrhythmias (ventricular tachycardia, ventricular fibrillation, atrioventricular block at degree II or above III), infarction after angina, recurrent myocardial infarction, and cardiac death.

Statistical analysis. SPSS 18.0 (Chicago, IL, USA) software was used for statistical analysis. Measurement data are 
presented as mean \pm standard deviation and the countable data were analyzed using the Chi-square test $\left(\chi^{2}\right)$. $\mathrm{P}<0.05$ was considered statistically significant.

\section{Results}

Comparison of baseline data. There were no statistically significant differences ( $p>0.05)$ for gender, age, body mass index (BMI), smoking, drinking history, concomitant diseases (hypertension, hyperlipidemia), and the biochemical criteria (blood routine examination, coagulation function, biochemistry full terms) of patients between the PPIs and control groups.

Comparison of gastrointestinal bleeding events and MACEs. Gastrointestinal bleeding occurred in two cases $(1.6 \%)$ of the PPIs group, including one case of occult bleeding and one case of minor bleeding, without severe gastrointestinal bleeding in this group. Additionally, there were 13 cases of gastrointestinal bleeding in the control group (15.5\%), including 5 cases of recessive bleeding, 5 cases of minor bleeding and 3 cases of severe gastrointestinal bleeding. There were significant differences $(\mathrm{p}<0.05)$ between the PPIs and control groups (Table I).

There were no statistical differences in the secondary onset of heart failure, severe arrhythmias (ventricular tachycardia, ventricular fibrillation, atrioventricular block at degree II or above III), infarction after angina, and recurrent myocardial infarction, as well as cardiac death in patients between two groups (all at p>0.05), (Table II).

\section{Discussion}

The administration of high doses of aspirin, clopidogrel and low molecular weight heparin in acute STEMI patients and their own perioperative stress response, particularly in patients undergoing PCI surgery, leads to a significantly increased risk of gastrointestinal bleeding (6). Numerous studies have shown its high incidence mainly during the first week of the course of disease $(7,8)$. To solve these problems, in the year 2008, the American Heart Association (AHA), American College of Cardiology Foundation (ACCF) and the American Society of Gastroenterology (ACG) jointly issued an 'Expert consensus to reduce the risk of gastrointestinal bleeding resulting from anti-platelet medicine and NSAIDS', suggesting that the patients with myocardial infarction should receive PPIs in parallel with antithrombotic therapy (9). That study indicated that the gastrointestinal bleeding events occurred in patients mainly during the first week after admission and pantoprazole significantly reduced the gastrointestinal bleeding event rate of patients with acute STEMI.

However, controversy exists regarding a possible interaction between PPIs and antithrombotic drugs. Gilard et al (10) designed a double-blind randomized controlled OCLA study and found that the administration of omeprazole together with antiplatelet PCI on day seven in patients resulted in a statistically lower platelet reactivity index $(P R I)$ than the control group $(p<0.05)$, confirming that omeprazole reduced the inhibitory effect of platelet P2Y12 receptor by clopidogrel. However, the research results presented by FAST-MI showed that the combined treatment of PPI together with omeprazole did not affect the clinical efficacy of clopidogrel. The results of the present study show that the short-term coadministration of pantoprazole did not increase the incidence of MACE events, indirectly supporting the results of FAST-MI (11).

However, there are some limitations to the present study, such as short duration, and small sample size, which may cause somewhat statistical deviations and inaccurate long-term prognosis of patients. These issues remain to be clarified in our continual follow-up and future studies. Other authors have also shown that the different PPIs had a different impact on anti-platelet medicines. For example, lansoprazole exerted the strongest inhibitory effects on anti-platelet function while pantoprazole and rabeprazole played a less suppressive role partially because the degradation products of pantoprazole and rabeprazole had a stronger inhibition to CYP2C19 (12). However, that study only tested the short-time function of pantoprazole, and did not compare pantoprazole to other PPI drugs nor observed its effect on platelet function. These issues are to be investigated in subsequent studies.

In conclusion, the short-term application of pantoprazole reduced the risk of gastrointestinal bleeding but did not increase the incidence of MACE events in patients with acute STEMI, thus being worth extending clinically, especially for high-risk patients.

\section{References}

1. Tamhane UU, Chetcuti S, Hameed I, Grossman PM, Moscucci M and Gurm HS: Safety and efficacy of thrombectomy in patients undergoing primary percutaneous coronary intervention for acute ST elevation MI: A meta-analysis of randomized controlled trials. BMC Cardiovasc Disord 10: 10, 2010.

2. Rogacka R, Chieffo A, Michev I, Airoldi F, Latib A, Cosgrave J, Montorfano M, Carlino M, Sangiorgi GM, Castelli A, et al: Dual antiplatelet therapy after percutaneous coronary intervention with stent implantation in patients taking chronic oral anticoagulation. JACC Cardiovasc Interv 1: 56-61, 2008.

3. Juurlink DN, Gomes T, Ko DT, Szmitko PE, Austin PC, Tu JV, Henry DA, Kopp A and Mamdani MM: A population-based study of the drug interaction between proton pump inhibitors and clopidogrel. CMAJ 180: 713-718, 2009.

4. Ho PM, Maddox TM, Wang L, Fihn SD, Jesse RL, Peterson ED and Rumsfeld JS: Risk of adverse outcomes associated with concomitant use of clopidogrel and proton pump inhibitors following acute coronary syndrome. JAMA 301: 937-944, 2009.

5. Bak-Romaniszyn L, Wojtun S, Gil J and Planeta-Malecka I: [Peptic ulcer disease etiology, diagnosis and treatment]. Pol Merkur Lekarski 17 Suppl 1: 128-132, 2004.

6. Chua SK, Liao CS, Hung HF, Cheng JJ, Chiu CZ, ChangCM, Lee SH, Lin SC, Liou JY, Lo HM, Kuan P and Shyu KG: Gastrointestinal bleeding and outcomes after percutaneous coronary intervention for ST-segment elevation myocardial infarction. Am J Crit Care 20: 218-225, 2011.

7. Derry S and Loke YK: Risk of gastrointestinal haemorrhage with long term use of aspirin: meta-analysis. BMJ 321: 1183-1187, 2000.

8. Ariza-Sole A, Sanchez-Elvira G, Sanchez-Salado JC, Lorente-Tordera V, Salazar-Mendiguchia J, Sanchez-Prieto R, Romaguera-Torres R, Ferreiro-Gutierrez JL, Gomez-Hospital JA and Cequier-Fillat A: CRUSADE bleeding risk score validation for ST-segment-elevation myocardial infarction undergoing primary percutaneous coronary intervention. Thromb Res 132: 652-658, 2013. 
9. Bhatt DL, Scheiman J, Abraham NS, Antman EM, Chan FK, Furberg CD, Johnson DA, Mahaffey KW and Quigley EM; American College of Cardiology Foundation Task Force on Clinical Expert Consensus Documents: ACCF/ACG/AHA 2008 expert consensus document on reducing the gastrointestinal risks of antiplatelet therapy and NSAID use: a report of the American College of Cardiology Foundation Task Force on Clinical Expert Consensus Documents. Circulation 118: 1894-1909, 2008.

10. Gilard M, Arnaud B, Cornily JC, Le Gal G, Lacut K, Le Calvez G, Mansourati J, Mottier D, Abgrall JF and Boschat J: Influence of omeprazole on the antiplatelet action of clopidogrel associated with aspirin: the randomized, double-blind OCLA (Omeprazole CLopidogrel Aspirin) study. J Am Coll Cardiol 51: 256-260, 2008.
11. Simon T, Verstuyft C, Mary-Krause M, Quteineh L, Drouet E, Méneveau N, Steg PG, Ferrières J, Danchin N and Becquemont L; French Registry of Acute ST-Elevation and Non-ST-Elevation Myocardial Infarction (FAST-MI) Investigators: Genetic determinants of response to clopidogrel and cardiovascular events. N Engl J Med 360: 363-375, 2009.

12. Li XQ, Andersson TB, Ahlström M and Weidolf L: Comparison of inhibitory effects of the proton pump-inhibiting drugs omeprazole, esomeprazole, lansoprazole, pantoprazole, and rabeprazole on human cytochrome P450 activities. Drug Metab Dispos 32: 821-827, 2004. 